\title{
A IMPRENSA E OS ASPECTOS DA HISTÓRIA DA EDUCAÇÃO DE UMA CIDADE DO INTERIOR PAULISTA (1928-1930)
}

\author{
Aline de Novaes Conceição \\ Universidade Estadual Paulista - UNESP, Programa de Pós-Graduação em Educação, Marília, SP. E-mail: \\ alinenovaesc@gmail.com
}

\begin{abstract}
RESUMO
Apresentam-se, resultados de pesquisa realizada com o objetivo de contribuir para a preservação da memória e produção da história da educação em Marília/SP. Para isso, focalizam-se os apectos dos textos sobre educação, publicados no jornal O Alto Cafezal entre 1928 e 1933, respectivamente ano do texto mais antigo localizado e ano do texto publicado antes da instalação da Comarca na cidade. Mediante abordagem histórica, centrada em pesquisa documental e bibliográfica, foi elaborado o documento Textos sobre educação nos jornais marilienses do acervo da Câmara Municipal de Marília/SP (1928-1933): um instrumento de pesquisa. A análise desse documento possibilitou constatar que houve um aumento da publicação de textos sobre educação nos números do jornal de Marília/SP e a imprensa mariliense era utilizada para reivindicar e registrar interesses da população inclusive os educacionais.

Palavras-chave: Educação em Marília/SP. História da Educação. Memória e História da Educação. Jornal. Imprensa.

\section{THE PRESS AND THE ASPECTS OF THE HISTORY OF THE EDUCATION OF A CITY OF THE PAULIST INTERIOR (1928-1930)}

\begin{abstract}
Present, research results carried out with the general aim of contributing to the preservation of memory and the production history of education in Marilia / SP (city state of São Paulo). For this, focus is the education aspects of the people on texts, published in the journal The High Cafezal between 1928 and 1933, respectively year older text located and Year text published before the District of facility in the city. By historical approach, focused on documentary and bibliographical research, it designed the texts document on education in newspapers marilienses the City Council's collection of Marilia / SP (city state of São Paulo) (1928-1933): a research tool. The analysis of this document possible to see that there was an increase in the publication of texts on education in the journal numbers of Marilia / SP and the mariliense press was used to claim and register interests of the population including education

Keywords: Education in Marília-SP (city state of São Paulo). History of Education. Memory and History of Education. Journal. Press.
\end{abstract}




\section{INTRODUÇÃO}

Apresentam-se neste texto, resultados de uma pesquisa realizada com apoio do Conselho Nacional de Desenvolvimento Científico e Tecnológico (CNPq), sobre a cidade de Marília/SP, que se situa na região Centro-Oeste Paulista e a área da cidade é de $1.194 \mathrm{~km}^{2}$; sendo $42 \mathrm{~km}^{2}$ de área urbana e $1.152 \mathrm{~km}^{2}$ de área rural, com aproximadamente 220 mil habitantes, a cidade é conhecida como a "Capital Nacional do Alimento".

Há uma escassez de pesquisas sobre a história da educação da cidade de Marília/SP, assim, a mais abrangente foi realizada por Tobias (1990a; 1990b) que apresenta aspectos da origem da educação primária da cidade. É necessário que haja pesquisas na área da história da educação, por contribuir para uma ação mais reflexiva por parte do sujeito, possibilitando a busca de uma mudança social, compreendendo que as mudanças que ocorreram possibilitam transformações presentes, pois não há vivências e nem histórias permanentes.

A partir disso, o objetivo geral da pesquisa cujos resultados estão apresentados neste texto, consistiu em contribuir para a preservação da memória e produção da história da educação em Marília/SP e os objetivos específicos consistiram em: contribuir para a compreensão dos textos sobre educação em Marília/SP e região publicados nos jornais marilienses; elaborar um instrumento de pesquisa sobre educação em Marília/SP e região; analisar as referências de textos contidas no instrumento de pesquisa e subsidiar o desenvolvimento de pesquisas correlatas.

\section{MÉTODO}

Para o desenvolvimento da pesquisa, mediante abordagem histórica centrada em pesquisa documental e bibliográfica, foram utilizados os procedimentos de localização, recuperação, reunião, seleção e ordenação de referências de textos sobre o tema publicados no jornal mariliense $O$ Alto Cafezal que teve circulação no período de 1928 a 1938. Para isso, foram consultados acervos físicos da cidade, site e bases de dados disponíveis on-line.

Da consulta, resultou o documento Textos sobre educação nos jornais marilienses do acervo da Câmara Municipal de Marília/SP (1928-1933): um instrumento de pesquisa ${ }^{1}$ (CONCEIÇÃO, 2012a), respectivamente ano do texto mais antigo localizado e ano do texto publicado antes da instalação da Comarca na cidade (junho de 1933), essa data, é também a data em que o documento utilizado como fonte para a pesquisa, completou a metade do seu ciclo de vida.

Nesse instrumento de pesquisa, reuniu-se uma grande quantidade de referências de textos sobre educação. Considerando a necessidade de rigor, atenção e tempo para analisá-las, foram selecionadas para análise, as referências de textos publicados entre 1928 e 1930 (CONCEIÇÃO, 2012b), o que constituiu em um segundo documento que foi analisado de acordo com o método da análise da configuração textual.

O conceito de "configuração textual" é utilizado neste texto como propõe Mortatti (2000, p. 31),

[...] conjunto de aspectos constitutivos de determinado texto, os quais se referem: às opções temático-conteudísticas (o quê?) e estruturais formais (como?), projetadas por um determinado sujeito (quem?), que se apresenta como autor de um discurso produzido de determinado ponto de vista e lugar social (de onde?) e momento histórico (quando?), movido por certas necessidades (por quê?) e propósitos (para quê?), visando a determinado efeito em determinado tipo de leitor (para quem?) e logrando determinado tipo de circulação, utilização e repercussão.

Dessa forma, a análise foi realizada considerando os aspectos constitutivos do sentido de um texto.

\footnotetext{
${ }^{1} \mathrm{O}$ conceito de "instrumento de pesquisa" é utilizado como essencial à pesquisa histórica, pois os "[...] instrumentos de pesquisa constituem-se em vias de acesso do historiador ao documento, sendo a chave da utilização dos arquivos como fontes primárias da História. " (BELLOTTO, 1979, p. 1).

Colloquium Humanarum, vol. 15, n. Especial 2, Jul-Dez, 2018, p. 75-83. ISSN: 1809-8207. DOI: 10.5747/ch.2018.v15.nesp2.001078
} 


\section{RESULTADOS}

A elaboração do instrumento de pesquisa é uma importante etapa da pesquisa, que poderá subsidiar trabalhos de outros pesquisadores, auxiliar na tomada de decisões para o encaminhamento da pesquisa e contribuir para visualizar o conjunto das produções e/ ou publicações sobre o tema pesquisado. Para a elaboração do instrumento de pesquisa mencionado, foram recuperados textos sobre educação do jornal $O$ Alto Cafezal que continham palavras como: "educação", "educar", "instrucção" ou "instrução", "escola" (s), "Escola Normal” ou "Escolas normaes", "Grupo Escolar" (es), "prof." (a ), "Jardim da Infancia”, "Ensino Secundario", "Ginasio" ou "Ginásio", "escolar" (es), "Créche", "ensinou”, "colegio" ou "collegio", "Ensino Primario", "ensinamentos", "educativa", "Escolas Reunidas", "Ensino", "estudo" (s), "ensinando". "Universitaria", "professor" (a/ es), "aluno" (s, a, as), "estudar", "professorado", "estudantes", "aulas", "Curso Superior", "ginasiano", "faculdade", "Curso primario", "ginasial”, "Universidade", para isso, realizei a leitura dos textos publicados no jornal. Também recuperei as referências de textos que estavam na seção "Columna Escolar" / "Coluna Escolar" e na seção "Ginasio de Marilia".

Após localizar, recuperar e reunir as referências de textos sobre educação em Marília/SP e região (CONCEIÇÃO, 2012a), normalizou-se de acordo com o documento Norma Brasileira de Referência (NBR) - 6023 (2002), da Associação Brasileira de Normas Técnicas (ABNT), ordenandoas para inclusão no instrumento de pesquisa.

Essas referências foram organizadas de acordo com cinco tipos de textos localizados: "Manchetes", "Artigos", "Notícias", "Notas" e "Anúncios", destaca-se que esses tipos de textos estão de acordo com a definição do Dicionário de Comunicação, do Rabaça e Barbosa (2001). Apesar de esse dicionário conter definições de 23 áreas, foram utilizadas as informações da área do jornalismo.

Assim, constituiu-se o documento analisado intitulado Textos sobre educação nos jornais marilienses do acervo Câmara Municipal de Marília/SP (1928-1930): um instrumento de pesquisa (CONCEIÇÃO, 2012b), em que há 295 referências de textos sobre educação publicados no jornal e em cada seção, as referências seguem a ordem em que os textos foram localizados, da data da mais antiga a mais recente.

\section{DISCUSSÃO}

A partir das informações contidas no instrumento de pesquisa selecionado para análise (CONCEIÇÃO, 2012b) no Quadro 1, observa-se a quantidade total de referências localizadas e reunidas, por tipo de texto.

Quadro 1. Quantidade de referências de textos sobre educação em Marília/SP e região, por tipo de texto

\begin{tabular}{|c|c|}
\hline Tipo de texto & $\begin{array}{c}\text { Quantidade de } \\
\text { referências }\end{array}$ \\
\hline Manchetes & 9 \\
\hline Artigos & 10 \\
Notícias & 17 \\
\hline Notas & 206 \\
\hline Anúncios & 53 \\
\hline TOTAL & $\mathbf{2 9 5}$ \\
\hline
\end{tabular}

Fonte: Textos sobre educação nos jornais marilienses do acervo Câmara Municipal de Marília/SP (19281930): um instrumento de pesquisa (CONCEIÇÃO, 2012b 
Com base na análise dos dados apresentados no Quadro 1, é possível constatar que, dentre as referências de textos localizadas e reunidas nesse instrumento de pesquisa, a seção "Notas" é a que reúne a maior quantidade de referências de textos sobre educação publicados no jornal mariliense. O número de referências reunidas nessa seção (206) corresponde a 69,83\% da publicação total sobre o tema. Esse fato se justifica principalmente por ser constante a publicação de várias notas na seção "Columna Escolar" do jornal O Alto Cafezal.

Como se pode observar, ainda, no Quadro 1, a seção "Manchetes" é a que reúne o menor número de referências (nove), correspondendo a 3, 05\% da publicação total sobre o tema. Dessas referências, apenas 13 são assinadas, no Quadro 2, há a relação dos nomes dos autores das referências de textos reunidas no instrumento de pesquisa selecionado para análise. Esses autores são: Gilberto Lustosa, Sylvio Barros, Jonas Costa, Mario Spinelli, Lourdes Rotelli, Aurelio Grassi, Bernadina Peres, Dinah V. Lopes, José Yamashita e Maria Apparecida Ferraz:

Quadro 2. Autores e a quantidade de referências de textos sobre educação, ordenados por tipo de texto

\begin{tabular}{|c|c|c|c|c|c|c|}
\hline Tipo de texto & Manchete & Artigo & Notícia & Notas & $\begin{array}{l}\text { Anúnci } \\
\text { o }\end{array}$ & $\begin{array}{l}\text { Total por } \\
\text { autor }\end{array}$ \\
\hline $\begin{array}{l}\text { LUSTOSA, } \\
\text { Gilberto }\end{array}$ & 2 & - & - & - & - & 2 \\
\hline BARROS, Sylvio & - & 1 & - & - & - & 1 \\
\hline COSTA, Jonas & - & - & 2 & - & - & 2 \\
\hline SPINELLI, Mario & - & - & - & 1 & - & 1 \\
\hline ROTELLI, Lourdes & - & - & - & 1 & - & 1 \\
\hline GRASSI, Aurelio & - & - & - & 1 & - & 1 \\
\hline PERES, Bernadina & - & - & - & 2 & - & 2 \\
\hline LOPES, V. Dinah & - & - & - & 1 & - & 1 \\
\hline YAMASHITA, José & - & - & - & 1 & - & 1 \\
\hline $\begin{array}{l}\text { FERRAZ, Maria } \\
\text { Apparecida }\end{array}$ & - & - & - & 1 & - & 1 \\
\hline Total por tipo de texto & 2 & 1 & 2 & 8 & 0 & 1 \\
\hline
\end{tabular}

Fonte: Textos sobre educação nos jornais marilienses do acervo da Câmara Municipal de Marília/SP (1928-1930): um instrumento de pesquisa (CONCEIÇÃO, 2012b).

Por meio da análise dos dados apresentados no Quadro 2, constata-se que Gilberto Lustosa, Jonas Costa e Bernadina Peres, foram os autores que mais publicaram textos sobre educação, publicando respectivamente, manchete, notícia e nota. A análise das informações do Quadro 2, também possibilitam a observação de que as notas são os tipos de textos em que há mais autores. Isso se justifica pelo fato de que, a partir de julho de 1930, na seção "Columna Escolar", passou a serem publicados textos assinados por alunos do Grupo Escolar.

No geral, 95,59 \% correspondem aos textos que não foram assinados entre 1928 e 1930, assim os textos assinados correspondem a 4, 40\% e desses, $61,53 \%$ correspondem aos textos assinados e publicados na seção "Notas".

Destaca-se que o autor mencionado Gilberto Lustosa, publicou no jornal O Alto Cafezal, em 12 e 19 de maio de 1929. Ele era médico e estudou na faculdade do Rio de Janeiro, com "[...] pratica dos hospitaes de Berlim e Rio [...]" (DR. GILBERTO..., 1929, [p. 2]). Atendia na cidade, em um 
consultório da rua Prudente de Moraes (DR. GILBERTO..., 1929). O médico Gilberto Lustosa, "[...] propõe, ao ser que se orienta à verdade e ao bem, educação a um tempo intelectual e moral [...]" (TOBIAS, R., 1990b, p. 82). Para ele, a educação deve ser "[...] física, moral e intelectual. Tem influência decisiva na formação do homem [...] A escola oficina de trabalho, onde vamos colher as primeiras instruções, devia ser também um sanatório, não só para o físico [...] como para o moral" (LUSTOSA, 1929, p. 1).

O autor Sylvio Barros publicou no jornal O Alto Cafezal, em 13 de janeiro de 1929, ele era professor e "[...] Inspetor do 64을 Distrito Escolar com séde em Cafelandia [...]". (BARROS, 1929, p. 1). Nesse texto publicado no jornal, o professor Sylvio Barros, em resposta ao pedido do jornal em questão, "[...] vem ao público com uma carta dirigida à redação do referido semanário. Excusandose, afirma ele ter enviado o ofício no 25, de 8 de março de 1928 [...]" (TOBIAS, R., 1990b, p. 7), nesse ofício, era proposto que se criassem quatro escolas no município, essa proposta foi aceita. Sylvio também propôs "[...] o concurso pra provimento das escolas públicas existentes na povoação. Entre as candidatas aprovadas, figurava a Srta. Porfíria Simões de Mello (hoje Porfíria Simões dos Santos) [...]". (LARA, 1991, p. 32).

Jonas Costa nasceu em Recife em 1900, mudou-se para Marília/SP em 1929, é tido como um dos pioneiros da cidade. Tornou auxiliar do secretario da Prefeitura Municipal e em seguida, secretário dessa Prefeitura, até 1930. Publicou no jornal O Alto Cafezal, em 15 e 22 de dezembro de 1929 e permaneceu na cidade até o ano de 1932 (MOREIRA; MAGALHÃES; 1936).

Mario Spinelli publicou no jornal O Alto Cafezal, em quatro de agosto de 1929. Ele, juntamente com Júlio Vitor dos Anjos, Sebastião Nascimento, Ezequiel Pais Bandim, Dimas Pinto da Fonseca e Belarmino Alves, organizaram em primeiro de maio de 1929, a "Liga Operaria Alto Cafesal e Marilia". Essa liga reunia os operários da cidade e os sócios abriram uma escola para que seus filhos pudessem ser atendidos, por esse motivo, Mario Spinelli e os demais nomes citados, foram denominados de "Campeões do movimento de solidariedade" (MOREIRA; MAGALHÃES, 1936).

Lourdes Rotelli Lourdes Rotelli teve seu texto publicado no jornal $O$ Alto Cafezal, em 27 de julho de 1930, nessa época, ela era aluna do Grupo Escolar e estava no quarto ano.

Aurelio Grassi teve seu texto publicado no jornal O Alto Cafezal, em três de agosto de 1930, nessa época, ele era aluno do Grupo Escolar e estava no terceiro ano. Atualmente, Aurélio Grassi é a denominação de uma rua da cidade de Marília/SP, localizada no Bairro Professora Liliana de Souza Gonzaga.

Bernadina Peres teve seu texto publicado no jornal O Alto Cafezal, em 10 de agosto e cinco de outubro de 1930, nessa época, ela era aluna do Grupo Escolar e estava no quarto ano.

Dinah V. Lopes teve seu texto publicado no jornal O Alto Cafezal, em 24 de agosto de 1930, nessa época, ela era aluna do Grupo Escolar e estava no quarto ano.

José Yamashita teve seu texto publicado no jornal O Alto Cafezal, em 21 de setembro de 1930, nessa época, ele era aluno do Grupo Escolar e estava no segundo ano.

Maria Apparecida Ferraz teve seu texto publicado no jornal O Alto Cafezal, em 28 de setembro de 1930, nessa época, ela era aluna do Grupo Escolar e estava no segundo ano.

Constata-se que dentre os autores que publicaram textos no jornal O Alto Cafezal havia médico, professor, secretário da prefeitura e alunos.

Apesar disso, não há textos da primeira professora da cidade de Marília/SP que em entrevista informa que na escola que lecionava havia apenas uma sala com: "[...] uma mesa tosca retangular e dois bancos. Servia de lousa uma tábua larga, pintada com pixe ou carvão. Havia um pote de barro, onde os alunos bebiam água." (SIMÕES ${ }^{2}$ apud TOBIAS, R., 1990b, p. 73) e os conteúdos das aulas eram:

\footnotetext{
${ }^{2}$ Porfíria Simões relatou esses e demais aspectos ao responder o “Questionário aos Pioneiros", utilizado por Rosmar Tobias, no livro, não se menciona o ano em que o questionário foi respondido.

Colloquium Humanarum, vol. 15, n. Especial 2, Jul-Dez, 2018, p. 75-83. ISSN: 1809-8207. DOI: 10.5747/ch.2018.v15.nesp2.001078
} 
[...] continhas, tabuadas e desenhos [...] aprendia-se a quantidade e em seguida os números. Todo fim de semana a aluna ou aluno que fossem mais comportados, aplicados, obedientes e assíduos teria o seu nome no quadro de honra. Então todos se esforçavam e também tomavam conta do armário, distribuindo e recolhendo os cadernos e livros. Havia aula de declamações e música. A caligrafia era escrita em cadernos próprios, sendo uma semana com a mão direita e a outra com a mão esquerda. (SIMÕES apud TOBIAS, R., 1990b, p. 73).

Na cidade, em 1928, foi fundada a Academia Comercial, oferecia os cursos primário e secundário e era dirigida pelo professor Guido Capello, cujo nome não foi localizado no instrumento de pesquisa. Ainda nesse ano, os japoneses construíram a primeira de muitas escolas japonesas construídas na cidade. No ano seguinte, na Avenida Sampaio Vidal, iniciou-se o funcionamento dos Grupos Escolares e também das Escolas Reunidas que assim como nos grupos escolares "[...] as disciplinas do curso primário são distribuídas pelo 10 e 20 ano, cada um a cargo de um professor e sob orientação e fiscalização constante de um diretor" (TOBIAS, R., 1990b, p. 82). Ainda em 1929, a Liga Operária abriu "[...] uma escola diurna mista para os filhos dos sócios e subvencionada pela municipalidade." (TOBIAS, R., 1990b, p. 83).

Em 1930, Durval de Menezes, primeiro prefeito da cidade, autorizou a criação de 14 escolas isoladas em Marília/SP. Nesse ano, foi fundado o colégio Santa Terezinha, era uma escola particular que funcionou até 1931.

Além dessa escola particular, havia outras como: Colégio Rio Branco, a Academia de Comércio Alto Cafesal, o Externato e havia também três escolas de ensino médio: "'Academia Comercial', do Prof. Guido Capello; 'Externato', da Diretora Albertina Ramalhal e Colégio 'Olavo Bilac', da Profa Norina T. Perez. Essas instituições não oficializadas tiveram duração de cerca de 1 ou 2 anos." (TOBIAS, R., 1990b, p. 128).

Em 1930, as Escolas Reunidas foram transformadas em grupo escolar, tinham-se 320 alunos matriculados e 500 crianças aguardavam vagas. $O$ diretor do primeiro grupo escolar foi o professor Balthazar de Godoy Moreira, considerado como exemplo de educador. Esse professor utilizava e divulgava os métodos da Escola Ativa, e reunia os professores para "[...] coordenar as atividades administrativo-docentes do Grupo Escolar, inclusive o movimento de implantação da Pedagogia Nova." (TOBIAS, R., 1990b, p. 114).

Os habitantes da cidade tinham contato com "[...] líderes da Pedagogia Nova [...] frutos de trabalhos desenvolvidos pelo movimento da Escola Ativa deslanchando em Marília." (TOBIAS, R., 1990b, p. 112). No jornal O Alto Cafezal, em 1931, foi relatado que o Professor Lourenço Filho "[...] um dos maiores líderes e implantadores da Escola Ativa no Brasil e especialmente no estado de São Paulo." (TOBIAS, R., 1990b, p. 112-113), visitaria a cidade.

Em 1931, o professor Balthazar Moreira enviou “[...] ao Diretor Geral do Ensino, Dr. Lourenço Filho, uma relação nominal de 320 crianças que não puderam ser admitidas no Grupo por falta de vagas." (TOBIAS, R., 1990b, p. 88). Ainda nesse ano, tornou-se diretor técnico do Jardim da Infância, criado por Maria Godoy (TOBIAS, R., 1990b).

Desse modo, em 1931, na cidade, havia “[...] duas instituições pré-primárias particulares. 0 Jardim da Infância, de Da. Maria Godoy, sob a direção técnica do Prof. Balthazar de Godoy Moreira, foi anunciado nos jornais desde os primeiros dias de janeiro [...]" (TOBIAS, R., 1990b, p. 101) e utilizava "[...] os métodos da Escola Ativa." (TOBIAS, R., 1990b, p. 114). Posteriormente, em fevereiro, instalou-se outro Jardim da Infância, com direção da professora Angelina Roselli.

Ainda em 1931, "[...] a Prefeitura Municipal de Marília cria as Escolas Reunidas Municipais de Marília. As quatro escolas isoladas que funcionavam no edifício da antiga prefeitura, à Rua 4 de abril, Foram transformadas em Escolas Reunidas [...]" (TOBIAS, R., 1990b, p. 125). Nesse ano, o professor Bártholo fundou "[...] o primeiro estabelecimento de ensino secundário que aqui se instalou: o 'Ginásio de Marília', que manteve, até fins de 1932 [...]” (TOBIAS, R., 1990b, p. 130). 
Nesse Ginásio, ministrou-se "[...] aulas do curso preparatório ao Ginásio e Escola Normal." (TOBIAS, R., 1990b, p. 131).

O ginásio também foi propriedade do Prof. Fill que o nomeou em “[...] Ginásio 'Olavo Bilac', origem do Ginásio Municipal de Marília, que é hoje em dia a Escola Estadual de 10 e 20 Grau 'Monsenhor Bicudo', de Marília." (TOBIAS, R., 1990b, p. 140).

Nesse período, o ensino secundário não era apoiado pelo município e pelo estado, apesar disso: "[...] os pioneiros de Marília, cientes do justo valor das suas conquistas, a tudo davam significação, particularmente no que diz respeito à educação, fruto em grande parte de sua própria iniciativa e de sua imprensa." (TOBIAS, R., 1990b, p. 133-134),

Em 1934, foi construído na cidade, o externato Sagrado coração de Jesus que pertencia às Irmãs Missionárias Zeladoras, cujo terreno, como mencionei, foi doado por Bento de Abreu Sampaio Vidal. Esse externato manteve o ensino primário até 1936 e em 1937, nele, ministraramse aulas do ensino secundário.

No geral, a educação da cidade era pautada na solidariedade:

[...] as realizações escolares, impregnadas de solidariedade, destacam-se a Escola da Liga Operária, inteiramente gratuita, mantida pela Liga Operária e subvencionada pela municipalidade; a Biblioteca Escolar, organizada pelo Prof. Balthazar de Godoy Moreira com doações oferecidas pelo povo da cidade [...] a Cooperativa Escolar, criada pelos alunos do grupo em fevereiro de 1931. (TOBIAS, R., 1990b, p. 163, grifo do autor).

Em 1934, estava integrado ao município de Marília/SP, “[...] os Distritos de Avencas, Pompéia, Oriente e Varpa [...]" (TOBIAS, R., 1990b, p. 94) e no município havia três Grupos Escolares, 11 Escolas Estaduais, 16 Escolas Municipais e 30 Escolas Particulares Primárias. Nesse ano, o prédio do Grupo Escolar, que atendia a cerca de 700 crianças, era tido como desqualificado, pois a sua estrutura física era pobre e antiga, sendo descrito como "casarão de tábuas", que não estava completamente pintado (TOBIAS, R., 1990b).

Em 1941, o ginásio municipal de Marília/SP ${ }^{3}$ passou a ser o Ginásio Estadual “[...] tendo em 1948 a Escola Normal Anexa como acréscimo [...]" (TOBIAS, R., 1990b, p. 150).

Em 2012, na cidade, havia cinquenta unidades de ensino municipais; quarenta e seis unidades de ensino estaduais; dezesseis escolas particulares; duas faculdades; uma fundação de ensino e três universidades (duas públicas e uma particular). Além das unidades de ensino, no município há o Centro de Apoio Psicopedagógico (CAP); redes de escolas de línguas, matemática e cursos profissionalizantes ${ }^{4}$.

Em 2011, a cidade foi destaque na imprensa devido à obtenção da média 6,4 no Índice de Desenvolvimento do Ensino Básico. Esses dados, segundo matéria do jornal Correio Mariliense:

[...] confirmam: Marília tem a melhor educação básica do país, nível que compreende do 1 ㅇa ao ano. Com a média de 6,4, cidade é destaque em reportagem na sessão "Especial Cidades" da Revista Veja desta semana. Entre os quesitos ressaltados na matéria estão a qualidade da estrutura educacional dispensada aos 18 mil atendidos pela rede municipal, capacitação dos professores e equipe gestora, além da presença indispensável dos pais na formação dos alunos [...] A média municipal, inclusive, é superior à meta estipulada pelo Ministério da Educação (MEC) para os próximos 20 anos, que é de 6 pontos (a mesma obtida em países desenvolvidos). (EDUCAÇÃO..., 2011a, grifo nosso).

Para divulgar essa notícia, a prefeitura da cidade distribuiu aos marilienses, exemplares de boletim informativo, cuja manchete era: "Educação de Marília é destaque nacional: Revista Veja mostra que é a melhor do país", (EDUCAÇÃO..., 2011b, grifo nosso).

Portanto, compreende-se que em Marília/SP, primeiramente constitui-se as escolas particulares, depois as escolas municipais e em seguida, as escolas estaduais (TOBIAS, R., 1990b) e

\footnotetext{
${ }^{3}$ Atualmente, esse ginásio é a Escola Estadual “Monsenhor Bicudo”, localizada na Avenida Rio Branco número 803.

${ }^{4}$ Informações obtidas em: <http://www.marilia.sp.gov.br/prefeitura/?page_id=361>. Acesso em: 28 set. 2012.

Colloquium Humanarum, vol. 15, n. Especial 2, Jul-Dez, 2018, p. 75-83. ISSN: 1809-8207. DOI: 10.5747/ch.2018.v15.nesp2.001078
} 
na cidade houve "[...] união da imprensa com os ideais do povo e da educação mariliense [...]" (TOBIAS, R., 1990b, p. 192), o que pode ser constatado ao consultar os jornais marilienses.

\section{CONCLUSÃO}

A população mariliense utilizou da imprensa para expressar seus desejos educacionais. Assim, a imprensa mariliense era utilizada para reivindicar e registrar interesses da população, inclusive os interesses educacionais e no jornal $O$ Alto Cafezal, a publicação de aspectos relacionados à educação também era estimulado pela criação das seguintes seções: "Ginasio de Marilia" e "Columna Escolar".

Em síntese, os resultados possibilitam compreender que no jornal O Alto Cafezal, cujas atividades iniciaram-se em primeiro de julho de 1928, o primeiro texto sobre educação foi um artigo publicado em 19 de agosto de 1928.

Além de artigos, entre 1928 e 1930, no jornal em questão, foram publicados outros tipos de textos para tratar de educação como: manchetes, notícias, notas e anúncios e, dentre os tipos de textos utilizados, na seção "Manchete" houve menos referências de textos e na seção "Nota" houve mais referências de textos. O que possibilita compreender que apesar de ser importante para o jornal, o tema educação não era primordial e dentre os textos publicados, havia o interesse em também publicar textos comerciais, ou seja, textos que vendiam vagas em escolas.

Os resultados da pesquisa desenvolvida também possibilitam compreender que houve um aumento de referências de textos sobre educação no jornal $O$ Alto Cafezal, principalmente entre 1929 e 1930, e o principal assunto das referências de textos sobre educação contidas no instrumento de pesquisa, foi "escola". Por fim, ressalta-se que a apresentação dos resultados dessa pesquisa contribui (singelamente) para a preservação da memória e produção da história da educação em Marília/SP e região.

\section{REFERÊNCIAS}

ASSOCIAÇÃO BRASILEIRA DE NORMAS TÉCNICAS. Norma Brasileira de Referências (NBR-6023). Rio de Janeiro, 2002.

BELLOTTO, Heloísa Liberali. Os instrumentos de pesquisa no processo historiográfico. In: Congresso Brasileiro de Arquivologia, 4, 1979, Anais..., p. 133-147.

CONCEIÇÃO, Aline de Novaes. Textos sobre educação nos jornais marilienses do acervo da Câmara Municipal de Marília/SP (1928-1933): um instrumento de pesquisa. Marília, 2012a (Digitado).

. Textos sobre educação nos jornais marilienses do acervo da Câmara Municipal de Marília/SP (1928-1930): um instrumento de pesquisa. Marília, 2012b (Digitado).

DR. GILBERTO Lustosa. O Alto Cafezal, Marilia, ano 1, n. 26, [p. 2], 12 maio 1929.

EDUCAÇÃO básica de Marília é destaque em revista Veja. Correio Mariliense, Marília, 1 nov. 2011a. Disponível em: < http://www.correiomariliense.com.br/materia.php?materia=18375>. Acesso em: 28 set. 2012. Não paginado.

EDUCAÇÃO de Marília é destaque nacional. Marília hoje, Marília , ano 1, n.1, 6 nov. 2011b. Não paginado.

LARA, Paulo Corrêa de. Marília, Sua Terra, Sua Gente. Marília: Iguatemy de Comunicações, 1991. 
LUSTOSA, Gilberto. Educação Escolar. O Alto Cafezal, Marilia, ano 1, n. 26, p. 1, 12 maio 1929.

MOREIRA, Balthazar de Godoy; MAGALHÃES, Alcides Lages. Marilia: cidade nova e bonita. Marília: Alto Cafezal, 1936.

MORTATTI, Maria do Rosário Longo. Os sentidos da alfabetização: São Paulo/ 1876-1994. São Paulo: Editora UNESP, 2000. https://doi.org/10.7476/9788539302697

RABAÇA, Carlos Alberto; BARBOSA, Gustavo. Dicionário de comunicação. 2. Ed. Rio de Janeiro: Campus, 2001.

TOBIAS, Rosmar. A educação de Marília: papel da imprensa (1925-1938). Marília: Unoeste, 1990a. 1990b. . História de Marília: Os Primórdios da Educação de Marília (1925-1938). Marília: Unoeste, 